\title{
Trends and concerns in digital cartography
}

\author{
M Visvalingam
}

\begin{abstract}
Digital cartography is the technology concerned with the construction and use of computer-based systems for the practice of cartography and its applications. The paper starts with a brief introduction to cartography and cartographic maps. It then provides an overview of some of the major trends and concerns in digital cartography. The subfields of visual and digital mapping are now well established and attention is being focused on more onerous activities, such as formal theorising about cartographic processes through automated production of maps; reliable and efficient management of integrated but changeable spatial databases; and, appropriate packaging of technology for geographical information systems. The paper also includes some comments on the contribution of CAD to cartography and on the not very well understood relationships between interactive cartography and the fast-growing, related disciplines of scientific visualization and geographical information systems.
\end{abstract}

digital cartography, geographical information systems, maps (geographical)

It is now widely accepted that the official definition of cartography, as stated by the International Cartographic Association, ${ }^{1}$ does not reflect adequately the wide scope and diverse concerns of the subject ${ }^{2,3}$. The Education Committee and Teachers Group of the British Cartographic Society have proposed that cartography is the science and technology of analysing, interpreting and communicating spatial relationships by means of maps ${ }^{4}$. The term 'map' is generic and includes geographic maps, plans, charts, sections, 3D models, globes and statistical diagrams. Maps are used for a variety of purposes and there are different conceptions of cartography; the geometric, technological, presentation, artistic and communication perspectives ${ }^{5}$ can be associated with different trends within cartography. The aim of this paper is to provide a personal interpretation and overview of some established and emerging trends and concerns within digital cartography.

Digital cartography refers to the fast-growing subdiscipline concerned with the use of information technology in the making and use of maps. The texts by Monmonier ${ }^{6}$, Carter ${ }^{7}$ and Burrough ${ }^{8}$ provide helpful introductions to some established trends within this subdiscipline. In the early days, cartographers were

Cartographic Information Systems Research Group, Department of Computer Science, University of Hull, Kingston-upon-Hull HU6 7RX, UK

Paper received: 11 August 1989. Revised: 18 January 1990 mainly concerned with using computer technology to automate map production. Tomlinson Associates, as reported on p 154 of a UK government publication", defined automated cartography as the use of computerbased systems for the more efficient production of maps. This involves the replacement of various types of manual activity, such as scaling, editing, colour separation, symbolization and typesetting, by computer processes. According to Morrison', the US Weather Service began to automate the plotting of daily weather maps in 1960, and the Oxford System for Automated Cartography was demonstrated in $1964^{10}$. This early preoccupation with automated cartography, which stimulated a series of international Auto Carto conferences (see, for example, Blakemore ${ }^{11}$ ), is now just one of many pursuits within digital cartography, as explained later.

In the following section, the traditional functions, essential properties, and two main types of maps are considered; this is useful for understanding the divergent trends within digital cartography, as described in later sections. The section on established trends begins with a brief description of early and more recent developments in visual mapping. It then introduces the concept of the digital map, some notable achievements within digital mapping, the use of digital maps within information systems that are not reliant upon graphic displays and some of the achievements and outstanding problems in the automated production of both digital and visual maps. The section on emerging trends considers the implications of advances in scientific visualization, visual computing and geographical information systems (GIS). The paper concludes by stressing that digital cartography provides the core of many (geo)graphical information systems.

\section{MAPS}

Visual maps form the focus of traditional cartography. They serve a variety of functions. The map is a medium for the comprehension, recording and communication of spatial relationships and forms; these are often, but not always, of geographical phenomena. Maps are designed to facilitate the extraction of all sorts of metrical and topological properties. They convey directly or implicitly information on location, direction, distance, height or magnitude, density, gradient, shape, composition, pattern, connectivity, contiguity, juxtaposition, hierarchy and spatial association. Unlike photographs, they are abstract models of reality and involve transformations of various kinds ${ }^{12}$. These include the geometric transformation of the spherical surface of the earth 
onto a plane surface by use of a systematic transformation, called a map projection ${ }^{5,13}$. The map is also usually a grossly reduced representation of reality, and it is insufficient merely to scale down the graphic representation since this would result in clutter and detract from the map's primary role as a communication medium. Thus, maps are generalizations; and the generalization of maps involves the application of processes, such as selection, classification, displacement, symbolization and graphic exaggeration.

All maps are symbolic and rely on the use of a graphic sign language. The design of the sign system and of its structure has been based on different premises. For example, one school within cartography has attempted to derive guidelines for map design from observations of users' sensory perception of visual variables, such as colour, balance, shape, size and texture. This artistic approach ${ }^{5}$ has provided some useful guidelines, but not a set of prescriptive mapping rules for achieving 'good design'. In contrast, the French cartographer Bertin ${ }^{14}$ attempted to relate elements of the graphic sign system to the information content of data. He proposed a rational and theoretical basis for graphic composition and design. His theory of graphics, which is intuitively appealing, has provided some prospects for the construction of expert systems for automating the design of displays of multivariate data, as attempted by Mackinlay ${ }^{15}$.

Map design is constrained by a number of factors, including scale (as previously described) and the purpose of the map. Table 1, from Visvalingam and Kirby ${ }^{76}$, illustrates some variations in concepts of reality and the aims of map making within scientific and artistic approaches. Reference maps, such as large-scale urban plans, topographical, geological and soil maps, and hydrographical and nautical charts, are regarded as scientific documents that aspire towards high standards of positional accuracy. Large-scale plans, which accompany the land register in some countries, are legal documents (called cadastral maps) that define land parcels for purposes of taxation, valuation and transfer of ownership. A characteristic feature of reference maps is that their design is constrained by the need to create one model of reality for a variety of purposes, including cartometry; they are visual databases. As a result, there is limited scope for artistic design.

In comparison, thematic maps, which are concerned with customized communication of derived information may be caricatural in their design. Cuff and Mattson ${ }^{17}$ provide a succinct and readable overview of thematic mapping. Examples of thematic maps include smallscale maps in population, agricultural and other census atlases, television weather maps, and other representations depicting some selected theme or class of phenomenon. Instead of overloading and cluttering each map with too much information, a set of maps is often used to portray different aspects of some theme of interest, such as the weather forecast. Designers of thematic maps have tended to preserve the data storage function of the map so that users could read off data values and/or classes. These maps often include diagrams, such as bar charts, flow diagrams and pie charts, to communicate statistical information ${ }^{18}$. Thematic maps tend to place greater importance on the distribution or spatial pattern of aspatial attributes, rather than on their positional accuracy. Thus, the background topographic information need not conform to the high standards expected of scientific and/or inventory documents, and are often generalized and even deliberately distorted so long as they serve the required purpose. Even so, all maps preserve logical and topological relationships. The classic map of the London Underground and Howe's cartograms ${ }^{19}$ of the distribution of disease and mortality are cited as extreme but effective examples of the use of artistic licence in the design of maps.

Reference maps often contain a great deal of explicit and even more implicit information, which has to be extracted by reading, analysis and interpretation. When designing thematic maps, the emphasis is on the direct and forceful communication of a message, which must be perceived almost intuitively rather than through a laborious process of map reading and analysis. For example, when forecasting the weather, meteorologists analyse and interpret detailed weather charts, depicting isobars, fronts and other conventional graphic jargon.

Table 1. Some variations in concepts of reality and aims in map making

\begin{tabular}{|c|c|c|}
\hline \multirow[b]{2}{*}{$\begin{array}{l}\text { Characteristics } \\
\text { of map model }\end{array}$} & \multicolumn{2}{|c|}{ Approach } \\
\hline & Scientific & Artistic/sociological \\
\hline Reality & Absolute & Manmade \\
\hline Requirement & Must be objective & Can be subjective or even mental models \\
\hline Emphasis & Faithful image of reality & $\begin{array}{l}\text { Communication of message or even } \\
\text { functional schema }\end{array}$ \\
\hline Detail & Can be very complex & Must be succinct and clear \\
\hline Purpose & General purpose; for reference & For customized communication \\
\hline $\begin{array}{l}\text { Expectations } \\
\text { of user }\end{array}$ & $\begin{array}{l}\text { Proficiency in map reading, analysis } \\
\text { and interpretation }\end{array}$ & Little map skill but familiarity with subject \\
\hline Examples & $\begin{array}{l}\text { Ordnance Survey Topographic Map; } \\
\text { Geological Maps; Admiralty Charts }\end{array}$ & $\begin{array}{l}\text { Thematic maps and business graphics, } \\
\text { often depicting results of analysis and } \\
\text { synthesis }\end{array}$ \\
\hline
\end{tabular}

Source: adapted from Visvalingam and Kirby ${ }^{16}$ 
A great deal of imagination and investment is expended on new designs for weather maps in the competition for television viewers ${ }^{20}$.

To recapitulate, maps are abstract and symbolic representations of reality and their production involves various kinds of transformations. The design of maps is constrained by a number of factors, especially the purpose of the map. At a simplistic level, it is possible to distinguish two classes of maps, namely reference maps and thematic maps.

\section{ESTABLISHED CONCERNS}

Visual mapping dominated digital cartography in the early days partly because of the limitations of early computer technology. Subsequent developments in auxiliary storage technology and the ever-increasing volumes of digital map and map-related data led to growing interest in a variety of issues within the subfield of digital mapping. Developments in digital mapping have furthered the output of both nongraphic and cartographic products and have led some researchers to propose a new definition of cartography. But these developments, like some recent developments in graphic human-computer interaction, have continued to emphasize the role of computers in the production, rather than use of maps.

\section{Visual mapping}

Even during the early days there were two different trends in digital cartography, namely automated cartography and computer-assisted cartography ${ }^{21}$. Some researchers, such as Rhind ${ }^{22}$, dismissed this distinction as a potentially 'dangerous and misleading one which obscures the identical nature of the data-handling in both "fields" at the machine level and the considerable overlap of the subject'. Both these trends are based on the same technology and methodology but they are guided by different objectives. As described earlier, automated cartography is concerned largely with replacing manual processes in the production of reference maps. Developments in computer-assisted cartography attempt to automate geometric calculations but not the creative element in the design and production of maps.

In the USA much of the early work on computer mapping was performed at the Harvard Laboratory for Computer Graphics and Spatial Analysis, which was established in 1965 under the direction of Howard T Fisher, who produced SYMAP. This command-driven batch program for generating line-printer maps of point and areal data is still available today, though with a somewhat different user interface. It produces areafilled choropleth maps (in which the polygons with uniform values are user-defined) and isopleth (contour) and proximal (Thiessen polygon) displays (where the polygons are interpolated between a set of userspecified points). It provides a complex set of options with defaults for both map generation and map design. From the very early days, therefore, a considerable amount of effort was expended not just in developing algorithms for effecting the required transformations and for generating the graphics, but also in abstracting and parameterizing the various types of design decisions involved in map making. With the advent of incremental pen plotters, the Harvard Laboratory released SYMVU, which generates 3D histograms, block diagrams and surfaces using the matrix of interpolated values either output by SYMAP or input by the user.

There has been a proliferation of programs and packages for generating statistical diagrams, 2D maps and oblique views of 3D data ${ }^{7}$. Many of these packages for computer-assisted mapping were originally developed as command-driven batch programs on mainframe computers. In theory, CRT displays and the vast number of design options offer considerable scope for experimenting with designs for selected areas, objects and features within databases. In practice, they inhibit experimentation by end-users since the design of the interface to these packages tends to assume that users have a programmer's mentality. Consequently, users have tended to identify some procedures that work and then stick to them. Some believe that the wide range of design options offer ample scope for bad design and prefer to use front-end macros provided by someone else with more technical expertise. This has encouraged a preplanned approach to the production of maps. Indeed, the most widely used packages, such as SYMAP and CIMMS'23, have been most extensively used for the production of atlases and for routine operational maps, both types of which tend to have a well-defined format and design. Even when there has been a user-interface lift, mainly by inclusion of a menu- or form-based style of interaction, the intention has been to guide users and reduce the scope for erroneous input. The user cannot directly modify the design. Instead, the user directly or indirectly has to modify the data and/or parameter file and regenerate the whole image.

Developments in the field of human-computer interaction ${ }^{24}$ and the scope for direct manipulation within CAD and WIMP environments ${ }^{25}$ have encouraged some previous users of powerful command-driven packages to return to the practice of near-manual cartography on the versatile medium of the CRT display instead of on paper. The Quantel Paintbox is already used in some applications of thematic mapping ${ }^{20}$. Not all map makers, however, have either the onerous mapping requirements or the mapping budget to justify the cost of state-of-the-art mapping and/or graphics systems. Many users, such as planning departments, produce one-off maps within reports. Despite their limitations, PC-based systems, AutoCAD, the Adobe Illustrator and PostScript printers are now widely used for incorporating stylized thematic maps and diagrams within documents designed to impress nontechnical decision makers. The ability to program and design one-off maps by seeing and pointing to functions, objects and attributes within an affordable environment is highly attractive to many end-users, who are adapting these environments to their own needs. For example, the Macintosh is used as a terminal to other computers running conventional mapping packages, such as GIMMS, to clip the display for subsequent editing using 'paint' or semi-intelligent sketchpad systems. The main 
theme of the 1990 Annual Conference of the British Cartographic Society is desktop mapping, which is becoming increasingly attractive to many practitioners within the cartographic profession.

\section{Digital mapping}

The full benefits of digital cartography can only be realized when the required data are already in computer-readable form. There is now a large primary sector within the computer mapping industry mainly concerned with the collection, processing, validation, maintenance and distribution of spatial data. This sector includes the national mapping agencies, such as the Ordnance Survey of Great Britain and the United States Geological Survey, various census organizations, including the Office of Population Censuses and Surveys of England and Wales and the United States Bureau of the Census, a number of private surveying, digitizing and scanning agencies, and those involved in the collection, processng and distribution of remotely sensed images ${ }^{9,26-28}$. Although early work in digital cartography had been concerned with conceptual, logical and physical models of vector and raster data ${ }^{29}$ and spatial data processing ${ }^{30-33}$, the rate of growth of spatial databases is necessitating research and development of even more efficient procedures for the capture, checking, editing, processing, compact storage, indexing, integration, update and retrieval of spatial data captured in different formats from numerous sources. The relatively new subfield of digital mapping (see Figure 1) is concerned with the creation, maintenance and performance of very large spatial databases.

Automated, computer-assisted and near-manual cartography focus on the visual map, which has traditionally been the principal product of cartographic activities. A new focus of activity within digital cartography is given prominence in Guptill and Starr's ${ }^{34}$ definition of cartography as 'an information transfer process that is centred about a spatial database which can be considered, in itself, a multifaceted model of geographic reality. Such a spatial database then serves as the central core of an entire sequence of cartographic processes, receiving various data inputs and dispensing various types of information products'. This definition of the subject makes the spatial database the focus of the subject and regards the traditional focus of activity, the visual map, as one amongst a range of information products as illustrated in Figure 1.

Both in theory and in practice the map database has become the ultimate reference map - the digital map, which is a commercial product in its own right. The archives of national mapping agencies, including the United States Geological Survey ${ }^{35}$ and the Ordnance Survey of Great Britain, will in future be held in digital rather than analogue form and, in Britain, users will be able to purchase on demand and to their own specification Customer Plots from Current Data (CPCD) from high-street retail outlets ${ }^{36}$.

A number of applications need to visualize these data. Visualization is especially necessary when cartographic/topographic data are minimally structured and held as raster- or video-scanned images as in the Domesday Project ${ }^{37}$, British Telecom's VMIS system, or

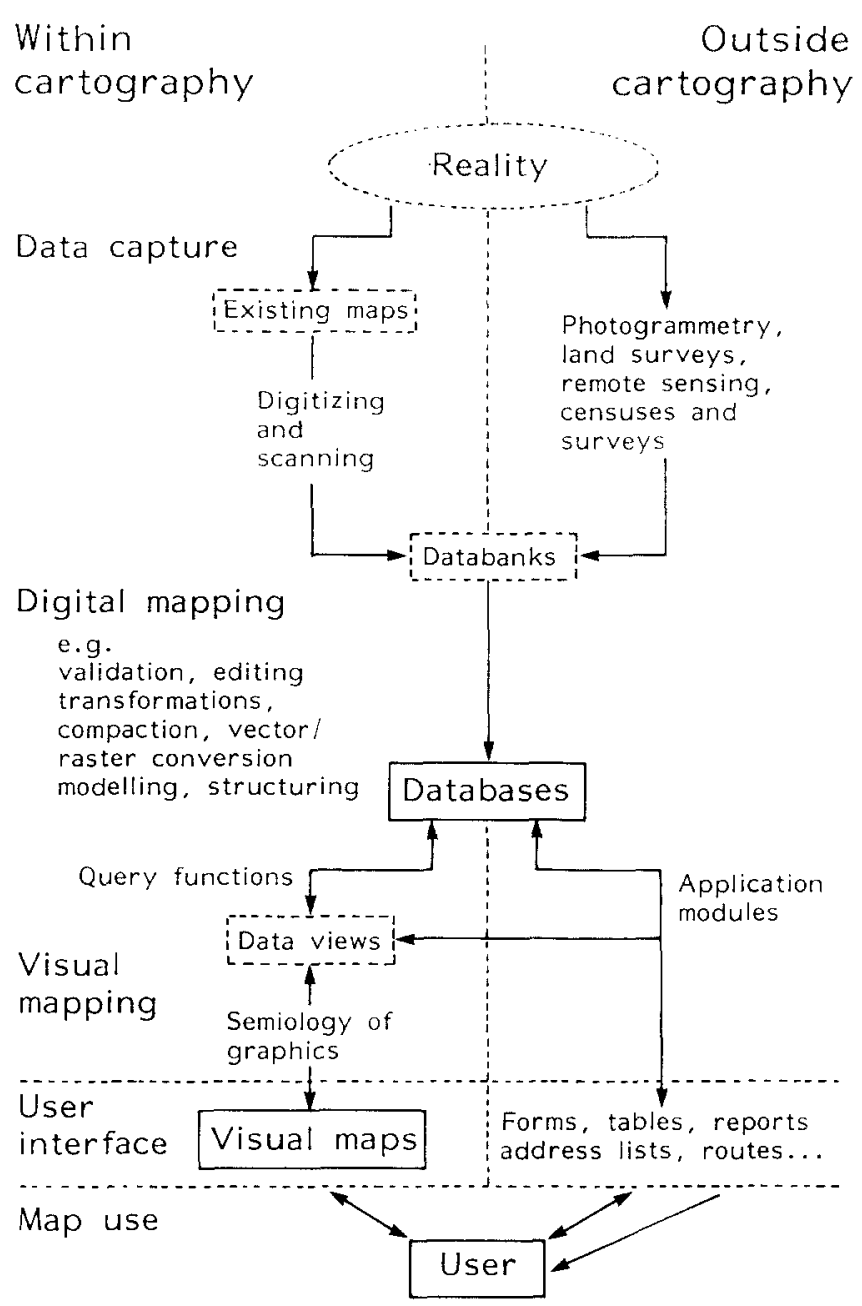

Figure 1. Scope of digital cartography (after Visvalingam ${ }^{3}$ )

in the map-based information system adopted by English Heritage ${ }^{38}$. Trade literature suggest that the previous mapsheet-based database is being replaced by spatially continuous maps to allow users to zoom and pan smoothly over an extensive area. User's own data are usually added as 'layers', which are superimposed on top of the base maps on display for visual analysis and comparison. Users can randomly retrieve and display such digital and analogue maps stored on optical disc. The age of the electronic atlas, anticipated by Monmonier ${ }^{39}$, is already here. Although the user interface allows users to take measurements off these maps, as in the BBC Domesday system, this can be extremely inconvenient as found by Maling ${ }^{40}$. Similarly, so-called spaghetti-digitized vectors, which have not been topologically structured, tend to be used as background maps. Until relatively recently Ordnance Survey large-scale digital maps were not topologically structured $^{36,41}$. Also mapsheets can overlap and, even where they do not, automatic edge-matching of digitized sheets is not a trivial task. The Ordnance Survey of Northern Ireland has been able to supply topologically structured and edge-matched background data since $1987^{42}$.

Limited amounts of data may be captured in a topologically structured form, using one of many defacto formats, such as the widely used CIMMS segment format ${ }^{23}$. These stipulate that lines should not cross except at junction points, called nodes. The user 
explicitly has to input these nodes and the codes for the hierarchy of areal objects to the left and right of boundary lines. This places an unnecessary burden on the user to ease computer processing. It is error-prone and contradicts the requirement for user friendliness in human-computer interaction. Moreover, it greatly increases the cost of bulk data capture.

Consequently, large-scale analogue-to-digital conversion of maps relies either on raster or video scanning or the digitizing of only the point, line and text features in a relatively free format, which need not conform to topologic standards. This approach to vector digitizing produces a feature-based, rather than an object-based, data model. In an object recording model all information pertaining to some object of interest, such as an individual address or highway, may be retrieved in a systematic and complete manner. For example, it would be possible to retrieve by name the complete set of boundaries of an areal object with all the detached parts and/or holes within $\mathrm{it}^{43-45}$. In a feature-based model this information is associated with fragmented features, which are scattered within the database, and may remain implicit.

Fragmented features tend to be displayed in an ad-hoc order; this not only detracts from the quality of the map user interface in human-computer interaction, but it also has performance implications at the levels of both software (for example, the number of polyline calls) and hardware (increase in pen-up and pen-down movements). Also, area fill and the accurate calculation of distances, areas and volumes require the explicit recording of line and area topology within the database. Experience has shown that an object-recording database expedites the update of both geometric and attribute data and the management of so-called change (historical) data and their chronology.

Although proprietary software has been developed for geometrically adjusting digitized vectors and establishing line connectivity ${ }^{46,47}$, the results are not entirely satisfactory ${ }^{48}$. Once the vectors have been transformed into a link-and-node connected structure, however, it is possible to extract the area topology by geometric processing ${ }^{45}$ and infer automatically a great deal of implicit information about mapped entities and make this explicit ${ }^{44,49}$

Durham ${ }^{50}$ described raster-to-vector conversion and autotracing, which derives an internal structured model of a drawing from the display image, as 'an innovation in human-computer interaction, a first step towards the intelligent sketchpad which has some basic knowledge of how the human eye sees shapes'. Wade ${ }^{51}$ and de Simone ${ }^{49}$ demonstrated how the computer could automatically recognize administrative hierarchies and user-perceived objects, such as houses, minor buildings, roads and pavements respectively.

Digital models of reality are more useful when they represent topographic, rather than cartographic, entities. The Ordnance Survey 1:50000 Small Scales Demonstrator (SSD) Database of Sheffield and Doncaster (Sheet 111) was captured from analogue maps. Cartographic databases tend to be incomplete because of the limitations imposed by the paper medium. To avoid clutter, only high-priority features and objects, such as highways and administrative boundaries, are recorded in their entirety. Other features, such as river networks, remain incomplete, especially in built-up areas. Also, often on a map, the direction of flow of rivers is implied by contours and line width and the process of digitizing does not make such information explicit. Consequently, the UK Institute of Hydrology is using the digital terrain model (DTM), produced by the UK Military Survey from height information captured from 1:50000 maps, to fill in by simulation such missing information and extract a complete flow-directed network of rivers and their catchment boundaries (Moore, personal communication). Peucker and Douglas ${ }^{52}$, Mark ${ }^{53}$ and Marks et al. ${ }^{54}$ have also used DTMs for identifying drainage basin catchment boundaries and river networks, and have described the problem posed by 'pits' in the DTM.

The use of digital maps within the rapidly developing and commercially important area of geographical information systems (CIS) is greatly facilitated by the recording of user-perceived objects. The objects recorded in the SSD database were manually chained. Clearly, this is not practicable for the identification of all objects in Great Britain. Manual processes are also error-prone and tend to gloss over any existing errors. Visvalingam and Sekouris ${ }^{48}$ suggested that area-objects in the SSD database could be automatically recognized if candidate seeds for the primitive regions ${ }^{45}$ could be extracted by scanning the colour separations used in printing. Structured digital map data were used by Mason et $a l .^{55}$ for segmentation and interpretation of remotely sensed images. Early automated, computer-assisted and near-manual cartography were mainly concerned with computerizing map generation for the human information processing system. Advances in digital mapping have already stimulated research into computer interpretation of maps based on heuristics so as to make explicit the required topological and semantic information in a cost-effective way; digital mapping has launched automated cartography into a new era.

A major difference between digital cartography and $C A D$ lies in the greater variety, complexity and sheer quantity of cartographic and thematic data, the varying constraints on their interpretation and graphic display, and in the variety of conceptual and pragmatic spatial data models in use. The relational database model is increasingly used for managing thematic attribute data but the topological data has been handled by specialized, often ad-hoc, subsystems. For example, in ARC/INFO ${ }^{47}$, the attribute data are handled by INFO, a relational DBMS, while the topological data are handled by the ARC system. ARC is based on the GIRAS model ${ }^{43}$ and the DLG-3 data format ${ }^{56}$ used by the United States Ceological Survey. These were in turn based on early work on data structures by Peucker and Chrisman ${ }^{57}$ and on topology by Corbett ${ }^{58}$. The United States Bureau of the Census, whose Dual Independent Map Encoding (DIME) model is widely cited for its pioneering role, has now switched to the TICER model ${ }^{59}$.

More recent studies have shown that static, topologically structured archives may be managed using the relational model ${ }^{41,60,66}$. Reference maps, whether analogue or digital, do not attempt to make all 
geometric, toplogical and semantic relationships explicit; a great deal of information remains implicit and is derived by analytical and interpretative processes. Commercially available DBMS need to be extended, at the very least, to undertake these processes in an efficient and user-friendly manner ${ }^{62-64}$. Responding to queries about complex spatial objects in a large database is an inherently difficult computational task.

Although the relational model has some known and lamented weaknesses when managing topological data, the scope for developing systems on modest system configurations and later porting them onto dedicated database machines is appealing. The mapping of static data does not require the same level of complexity as expected within a system for interactively editing and merging clients' data and the base map. The abstraction of minimal conceptual models and functionally appropriate pragmatic models of both static and dynamic 2D spatial data is still the subject of research ${ }^{48}$. Loudon $^{65}$ gives a flavour of the problems inherent in modelling complex geological data in 3D.

Given the size of integrated spatial databases, the efficiency of storage, retrieval and performance are major considerations. Knowledge-based techniques are being investigated to guide search ${ }^{66}$. A great deal of research has been focused on spatial queries - not just for windowing but also for supporting relational operations on topological data and for polygon handling ${ }^{8,64}$, as undertaken within $\mathrm{ARC} / \mathrm{INFO}^{47.67}$. The problems of polygon intersection and spatial indexing are not unique to digital cartography. Bounding rectangles, or envelopes, have been widely used in range and quadtreebased searches ${ }^{68,69}$. Ballard ${ }^{70}$ and Shneier ${ }^{71}$ have also investigated strip trees and edge quadtrees respectively for representation of linear features.

Research effort is being directed at developing more efficient storage and search strategies particularly since there is now considerable interest in the integrated management of vector and raster data, for example in the conjoint use of topographic data and satellite images. This is impeded largely by the limitations of existing designs for vector data. Early solutions involved the conversion or discretization of vector data into a common raster form to facilitate comparisons based on proximity and Boolean algebra ${ }^{72}$. Such an approach facilitates logical and statistical analysis but impedes structural analysis since the topology of the data becomes blurred. Even the widely cited Peuquet's vaster encoding is subject to this limitation since it represents vectors as Freeman chain codes with a resolution determined by the raster data ${ }^{29}$.

More recently, others have investigated variants of two basic schemes for linking vector and raster data while preserving the geometric quality of vector data. Volatile spatial databases are modelled using pointerbased region quadtrees as proposed by Samet and coworkers (see for example, Ibbs and Stevens ${ }^{73}$ ) but static databases are represented more compactly and indexed using pointerless linear quadtrees as proposed by Gargantini ${ }^{74}$. Linear quadtrees offer considerable advantages for compact encoding and efficient processing of image data and, for spatial indexing, are superior to the more compact $2 \mathrm{D}$ run-length encoding (2DRE) proposed by Lauzon et al. ${ }^{75}$ The elegance of the quadtree structure has captured the imagination of a number of researchers, who seek to fit vectors into this scheme ${ }^{76}$ or adaptations of $\mathrm{it}^{77,78}$ (Newell and Theriault, personal communication). But quadtree indexing of vectors involves exhorbitant overheads (see for example the statistics quoted by lbbs and Stevens ${ }^{73}$ ) and there is insufficient published evidence to commend the use of quadtrees with vector data at present. Clearly there is a need for further research in this area

The problem of integrated use of vector and raster data structures is not unique to digital cartography and GIS. They are equally important within other applications of computer graphics. The demand for direct manipulation in human-computer interaction is directing research effort towards improving the integrity and performance of screen update when displaying vector data on low-cost raster refresh terminals ${ }^{79,80}$. Unless the requirements of these various tasks are considered together, separate techniques for essentially similar and related tasks will lead to unnecessary complexity and inefficiency within digital cartography and GIS.

The digital map is not therefore just a computerreadable file of map data. Visvalingam ${ }^{3}$ proposed that the term implies 'a compact, structured, integrated and elegant representation of spatial data and their aspatial attributes in a manner that facilitates rapid inference and retrieval and speedy but error-free update of data. This implies preprocessing and substantial restructuring of input data so that the digital postprocessing system may infer spatial forms, relationships and patterns in a way which matches, and if possible surpasses, human information processing capabilities'. This definition excludes uninterpreted raster and video-scanned images and spaghetti vectors, despite their value and use as visual maps.

Much progress has been made towards the establishment of a common vocabulary and standards for the exchange of topographic data at a national level, even if not an international one ${ }^{81,82}$. Also, many applications need to relate thematic and statistical data from different sources. The problems involved in linking data were outlined in the Chorley Report ${ }^{9}$, in which a number of useful recommendations were made to minimize these problems. The quality of data or its fitness for purpose is another important issue. One of the roles of the recently formed Association of Ceographic Information is to influence the establishment of standards.

\section{Nongraphic products based on digital maps}

Graphic visualization of the data is necessary in many, but not all, map-based applications. When a user is confident of the quality and appropriateness of the data and of the procedures for operating on them, highly structured databases enable many routine applications to function without the previous requirement for visual maps. Data need not be visualized as maps in order to schedule, time and cost the cutting of grass verges, the cleaning of streets or the salting of roads; to route vehicles using in-car navigation systems or to check the mileage on travel expense claims; or for 
computing cut-and-fill from terrain models in highway engineering.

The digital map has become the ultimate reference map for 'map reading', cartometric, other analytical, inferential and cross-referencing purposes. In many local authority applications the paper map was used as a means of cross-referencing and accessing spatially related textual and numerical information. Within a computerized environment, the base map need not appear within the user interface. For example, development staff in a local planning authority would ideally like to input a site address and pull out the planning constraints that apply to it for input into other pre-existing software. These constraints are normally recorded 'on', i.e. related by overlays to, a large-scale base map. As expressed by Weights ${ }^{83}$ ( $p$ 9), 'if the map is a necessary but intermediate step in answering an enquiry, then it makes for greater efficiency to the map users if that intermediate step is hidden, and the results of the geographical search displayed on a low-cost conventional terminal'. The lack of need for visual maps in some applications has led some to conclude that such activity falls within the field of GIS rather than digital cartography; but, as explained by Weights, the interlinking of data is reliant upon use of fully structured digital maps. Digital cartography provides the backbone of many GIS.

\section{Developments in automated and computer- assisted cartography}

There has been notable progress in automated cartography both with respect to automatic interpretation, as described earlier, and in visual map production. Many of the processes involved in the production of the digital version of the Ordnance Survey 1:625000 scale Route Planner map were automated ${ }^{84}$. Research into automatic name placement (for example by $\mathrm{Cook}^{85}$ ) had not progressed far enough in time to avoid interactive positioning and scaling of names. The Ordnance Survey is also using its home-grown system for in-house Automated Map Production (AMP) and for producing maps to customer requirements. These systems are not fully automated at present since manual checks and edits are still necessary ${ }^{86}$.

The move towards automation has necessitated some redesign, elimination of some content ${ }^{84}$ and modifications to the graphic ${ }^{87}$ to achieve results in the short term. For example, the conventional hachures have been replaced by special area fill symbolism. While in general traditional cartographers accept and endorse the semiautomated map products of the Ordnance Survey, they are highly critical and dismissive of the type of output produced by some others. However, many applications do not need the quality of displays achieved by professional cartographers even though some minimum standards are expected. Some system developers do, on the other hand, have the naive belief that map-based information systems can be constructed by simply fronting a database management system with software for computer graphics or CAD. Essinger ${ }^{88}$ indicated the type of functions that should be included within a CAD workstation for map design; and map design is just one requirement within digital cartography.

It is equally naive to assume that poor map design is solely due to a lack of cartographic training. Research into use of Bertin's ${ }^{14}$ cartographic theory within expert systems ${ }^{15}$ is still in its infancy and even when further advanced will be inadequate for fully automating design since this would also require automatic symbol and name placement and generalization of displays (see earlier discussion on maps as transformed representations and generalizations of reality). Research on subtasks, such as line simplification, has yielded a number of competing algorithms ${ }^{89}$, including those based on the idea of self-similarity ${ }^{90}$, but no substantive theory (despite the title of the paper by Peucker ${ }^{91}$ ) to guide their use. Objective mathematical evaluations of some of these algorithms by McMaster ${ }^{92}$ and Muller ${ }^{90}$ have also been misleading (see critique by Visvalingam and Whyatt ${ }^{93}$ ).

Whereas simplification of information and graphic design are often undertaken simultaneously in manual generalization, in digital cartography there is a need to distinguish between information generalization and display generalization; the former contributes to digital mapping, the latter to visual mapping. Both types of transformations are intellectually demanding and involve a variety of subtasks and processes. It is widely accepted that the long-term national objective of scale-free mapping, recommended by both the Serpell ${ }^{94}$ and Chorley Committees ${ }^{9}$, is not feasible given the current state of knowledge. Many applications use maps of the same entities compiled at a variety of scales with different content and symbolism. Route planning and the modelling of the hydrological cycle are mainly interested in the topologically connected network of centre lines of linear objects. Many land information systems, on the other hand, focus on the land parcel and are concerned with the areal extent of such linear objects. A number of users, such as in local government, need both detailed and simplified representations of the same objects.

At present, scale-related requirements are met by multiple definitions of the same areas. Within the UK Hydrographic Department, important points at each scale are manually identified and transferred onto large scales so that only the largest scale map is vector digitized. Each point is thus only digitized once. The scale of display appropriate for each feature is also recorded within a scale-integrated database ${ }^{95}$. Systems based on raster/video images zoom by retrieving images captured at the next larger scale ${ }^{37}$. Other researchers are manually integrating road networks captured at different scales for route planning (Chapman, personal communication) and are investigating database designs for supporting scale-free mapping ${ }^{78}$. Brassel and Weibel ${ }^{96}$ refer to earlier reviews and describe more recent work on the theme of automatic generalization.

\section{EMERGING TRENDS}

Whereas established trends tend to concentrate on the generation of maps and map-related products, the 
emerging trends focus attention on the interactive use of maps within both routine and creative applications.

\section{Scientific visualization - realism versus symbolism}

Advances in spatial data processing and in computer graphics have facilitated the visualization of 3D geographical phenomena, such as surface terrain and cover ${ }^{8,30.97}$. Some applications were outlined by Petrie and Kennie ${ }^{98}$ and others are described briefly in papers in Blakemore ${ }^{11}$.

Some of these applications will benefit directly from advances in visualization technology ${ }^{99,100}$; examples include visual impact analysis of proposed developments, such as installation of electricity transmission lines on the environment ${ }^{101}$ or the construction of a dam (see colour plates by International Imaging Systems in Burrough ${ }^{8}$ ). A computer-generated video movie of a simulated flight over a model of Los Angeles, constructed using a DTM and remote-sensed data, indicated the level of realism which could be achieved using Landsat satellite images with $30 \mathrm{~m}$ pixel resolution ${ }^{100}$. A pixel resolution of $10 \mathrm{~m}$ is available with Spot imagery.

It is important to stress that the current thrust towards detailed realism in computer graphics does not further all cartographic applications. The realistic visualization of terrain models is consistent with the scientific paradigm that guides the production of reference maps. The DTM is a reference map from which measurements may be made and reference maps aim to produce a faithful representation of reality subject to prevailing constraints (see Table 1). But not all 3D representations aspire towards realism; indeed, cartography is often used to communicate entities that exist by virtue of dictum, such as boundaries, and to explore and understand concepts and phenomena that are not directly observable; i.e. to see the unseeable. Concept refinement often relies on symbolic representation of multivariate proxy data (see section on interactive visual computing).

Depth cues are already used in manual cartography. They include aspect relief mapping, systematic hachuring, relief shading, panoramic views and block diagrams (illustrated in $\mathrm{Kraak}^{102}$ ) among other oblique views of land and townscapes. These hand-crafted oblique views were genuine maps since the representations were simplified and symbolic, rather than realistic. Indeed, the process of adding calculated realism to abstract descriptions of objects and scenes is contrary to the main aims of cartography. The latter, as noted earlier, employs a variety of transformational processes to derive abstractions about reality and communicate these through graphic symbolism. Cartography is more concerned with discovering and communicating the quintessence of reality rather than with achieving a photographic record of the real thing. A cartographic map is thus a graphic precis of reality. Sasada's ${ }^{103}$ work on the 'realism of drawing' is therefore highly relevant.

Geographers have been using DTMs for generation of orthogonal shaded relief maps for some time now ${ }^{8}$. There could well be a revival in use of symbolic oblique views of terrain within interactive applications, where the speed of human information processing in real time is as important as computer performance. As noted earlier, cartographic processes evolved to facilitate rapid and accurate information processing by the user. The research on advanced cockpit design within British Aerospace is concerned with the generation and use of symbolic 3D maps based on DTMs, satellite remotesensed and other data (Wills, personal communication). The DTM has become the base 'map' in 3D thematic mapping. Like the base map, the DTM has to be generalized to communicate the message effectively. Automatic generalization is one of the outstanding challenges in cartography and the appropriate generalization of oblique views of DTMs for specific purposes opens up new directions of research.

There are other developments within visualization that are relevant to cartography. The SICCRAPH video (Herr and Zaritsky ${ }^{100}$, p1.5) includes an animation sequence produced by the Human Factors Research Division at NASA's Ames Research Center. The researchers have combined the Data Clove with a speech recognition device and head position sensors to control a head-mounted display system with two liquid crystal display units presented to each eye. The virtual (mental) image created by the stereo pair appears to surround the user in 3D space. The operator is able to view this image from multiple viewpoints and explore and interact with this environment as if it was real. The video only shows use of wireframe displays.

The use of virtual maps is not new in cartography and photogrammetry. Kraak ${ }^{102}$ listed the visual expedients that have been used in cartography for enhancing depth perception when using two images. These include the optical stereoscope, anaglyphs and polarization. Kraak used computer displays of pairs of oblique views to establish whether viewing the map images in stereo led to improved performance. In his experiments Kraak not only used DTMs and urban scenes but also thematic 3D point symbol and prism maps, which are already used as mono images in cartography. He concluded that, provided that they were relatively simple in design, use of stereo pairs resulted in faster, but not necessarily better, processing of the map. Gugan and Dowman ${ }^{104}$ described the design requirements and problems involved in developing a digital stereo plotter for extracting topographic map data from Spot satellite imagery. Their paper included brief comments on various methods for digital stereo viewing and on some tentative solutions to the problem of Z-control when using the tracker ball as an input device to the host image processing system. Donoho et al. ${ }^{105}$ used kinematic displays to enhance the perception of point-clouds rotating in three-dimensional space. Statisticians are also using cartographic techniques within scatter plots (point distributions) of high-dimensional data ${ }^{106}$. Thus, advances in scientific visualization will benefit a number of cartographic applications.

\section{Interactive visual computing and cartographic exploration}

The Report of the Panel on 'Graphics, Image Processing and Workstations', sponsored by the Division of 
Advanced Scientific Computing (DASC) of the US National Science Foundation (NSF), advocated the view that the purpose of [scientific] computing is insight, not numbers' (McCormick et al. $.^{99}, \mathrm{p} 3$ ). It believed that 'The most exciting potential of widespread availability of visualization tools is not the entrancing movies produced, but the insight gained and the mistakes understood by spotting visual anomalies while computing'. Unfortunately, the accompanying SICCRAPH videotape $\mathrm{e}^{100}$, produced to illustrate the pioneering efforts in visualization, is mainly concerned with workstation trends, expansion boards, input/output peripherals, lighting, animation and parallel processing. The illustrations of scientific visualization, medical imaging and volumetrics and discussion of future trends tend to emphasize illuminations of synthetic reality. A student could be forgiven for concluding that interactive visual computing is mainly about changing one's viewpoint within an illuminated geometric model of reality.

As described earlier, advances in 3D visualization do benefit some applications of cartography. However, many scientific and sociological data are multidimensional and the step up from 2D to $3 \mathrm{D}$ is not sufficient to overcome the visualization problems. Under scientific and engineering research opportunities, McCormick et al..$^{99}$ ( $\mathrm{p} \mathrm{A}-8$ ) stated that ' With visualization techniques an analyst can work with many different, related data sets on a display screen; for example, one can use computer generated markers to show exactly how different images correspond'.

Visvalingam and Kirby ${ }^{16}$ and Visvalingam ${ }^{107}$ had previously expressed the view that the developments in workstation technology, concurrency and windowing systems offered some prospects for overcoming the problems of hyperdimensionality and provided a detailed account of how cross-referencing elements in a set of displays led to insight about sociospatial data. In geographic research, understanding has been furthered by comparing distributions of both individual and aggregate elements in a set of maps in conjunction with use of tables of raw and processed statistics.

Semimanual cross-referencing and exploring of the information content of multivariate data was laborious even when the spatial statistics related to a relatively small set of data collection units. Computer technology has facilitated the collection, statistical analysis and display of data for a very large number of units of much higher resolution; but systems for easy visual crossreferencing and exploration are not yet available, partly because of the limitations of past technology.

State-of-the-art GIS, such as ARC/INFO, do not provide the necessary facility and the SICGRAPH video, representing the state-of-the-art in scientific visualization, does not refer even to this requirement. Visvalingam ${ }^{108}$ suggested that there was a need for a rethink on systems design for interactive graphical information systems since many advanced CIS were not developed for multiprocess operating systems. An early prototype, on a $1 \mathrm{Mbyte}$ ICL Perq 1 computer running an extended version of Unix, for illustrating the use of maps as two-way human-computer communication devices, was limited by the available technology and the limitations of the Graphical Kernel System, GKS ${ }^{108}$. There is a lack of adequate support for such investigative work in the UK, where the funding policy is more supportive of 'near market' research and development. In contrast, the US National Center for Ceographic Information and Analysis (NCGIA), funded by NSF, has identified 'visualization research pertaining to the display and use of spatial data' as one of five priority areas for research ${ }^{109}$

The emphasis to date in visual mapping (as in computer graphics in general) has been on picture generation and, to a lesser extent, on picture interpretation. Even developments in graphic human-computer interaction have been oriented largely towards picture manipulation in the context of picture generation with intelligent sketchpads. After the extended initial preoccupation with enabling WIMP environments for graphic interaction, there is now a keenness to go beyond iconic interfaces and use the language of graphics more fully within the user interface. Icons act as pointers or represent information of a nominal kind. Researchers in human-computer interaction ${ }^{15,24,110}$ have more recently appreciated the need to take advantage of the wealth of knowledge within cartography and graphic design.

Visual mapping has focused on the communicative role of graphics. But the language of graphics is not just a means for communication. Like mathematics and the natural languages, the visual language provides a means for exploring and crystallizing thought. Bertin ${ }^{14}$ compared and contrasted graphics with other languages.

\section{Geographical information systems and digital cartography}

There is considerable confusion, at present, over the meaning of the term $\mathrm{GIS}^{27}$. Even prominent researchers in this field have expressed different opinions. Mark ${ }^{111}$ defined a GIS as 'a computerized, spatially-referenced data base organized in such a way that spatial data input, analysis, and output may be accomplished'; i.e. he equated it with the digital map. Others, such as Smith et al. ${ }^{66}$, regard this as the simpler form of a CIS. Their description of the field of CIS tended to emphasize the development of deterministic, probablistic and other heuristic procedures for increasing the efficiency of storage, retrieval, analysis and display of multisource spatial data; i.e. their definition of CIS is very similar to Guptill and Starr's definition ${ }^{34}$ of the new cartography. They too saw the spatial database as the focus of attention. Coppock and Anderson ${ }^{112}$ described GIS as 'a rapidly developing field lying at the intersection of many disciplines - among them cartography, computing, geography, photogrammetry, remote sensing, statistics, surveying and other disciplines concerned with handling and analysing spatially referenced data'. Just as the superdiscipline of scientific visualization is seen as an integration of computer graphics, image processing, computer vision, computer-aided design, signal processing and user-interface studies, GIS is regarded by some as the superscience concerned with geographically referenced data; the name of the UK Economic and Social Research Council/Natural Environment Research Council (ESRC/NERC) CIS Science Steering 
Committee contributes to this image making. Consequently, others have begun to relabel their activities as GIS, adding to the confusion. The following description of the relationships between GIS and digital cartography must therefore be read as a tentative personal interpretation.

Even if we ignore the confusion resulting from over-zealous promotional activities, the term CIS will mean different things to different people. This is not surprising given the variety of geographic data and the diversity of users and uses as catalogued in the Chorley Report $^{9}$. At the British Computer Society GIS Specialist Group's meeting in May 1989 on 'What do I expect from my GIS?', the invited speaker from English Heritage expressed in his introduction that he was unsure as to whether their map-based information system was a GIS. Many of the requirements outlined by Dale at the same meeting also related to the acquisition, management, manipulation and display of maps and map-related data.

Indeed, to many map users, a CIS is a digital and/or visual map-based information system. Consequently, digital cartography provides the infrastructure for many GIS applications. Maps are central to many landand property-based information systems, which are concerned with factual information about locations and places; the basic spatial unit (BSU) in these applications tends to be an appropriately defined link or a land parcel $^{9,173-175}$. The set of BSUs on a map may be regarded as forming one spatial coverage. The map and associated gazetteer are used to cross-reference and retrieve data for administrative and operational purposes within management information systems ${ }^{116}$. As previously described, some applications do not see visual maps as essential but others, such as the utilities ${ }^{117}$ and the Land Registry ${ }^{118}$, regard them as vital to their functions. The recording and routine selective retrieval and display of data on a single coverage is the least onerous application of digital cartography. Even here, proprietary DBMS and CAD software are insufficient although inventory systems are being launched with raster or video-scanned data. There is some disagreement (see later) as to whether such inventory and recording systems fall within the remit of GIS.

Although the utilities and local authorities use common base maps, they tend to operate with different sets of BSUs on separate coverages. In the UK, the 1950 Public Utilities Streets Works Act requires that public utilities exchange information concerning their mains and plant records. This Act has forced a collaborative approach towards solving the problem of inter-coverage comparisons within computerized systems ${ }^{119}$. The GIS for Northern Ireland was designed to facilitate data sharing ${ }^{42}$. A number of other GIS applications, including forestry, agriculture and conservation, also need to compare data on different map coverages on demand. This was traditionally done using a light-table. Often the aim is to identify target/critical areas with the required combination of characteristics. Within computerized systems, so-called overlay analysis may be undertaken in raster and/or vector formats using ad-hoc or general purpose systems ${ }^{120-122}$. Both approaches pose their own problems but the vector approach is conceptually and computationally more demanding CIS tools include facilities for integration of vector and raster data on different coverages.

Even when polygons describe geographical phenomena with clearly recognizable boundaries, as in choropleth maps, inherent generalization errors in source documents and inevitable errors introduced during data capture and/or processing produce spurious polygons on overlay. The automatic 'cleaning up' of spurious polygons is not a trivial or reliable process. When the data are captured from analogue sources compiled and generalized at different scales, existing facilities for scaling and intersecting polygons are inadequate. Map compilation requires the matching of generalized and displaced features and adjustment of the geometry prior to compilation. Saalfeld ${ }^{123}$ provided a detailed and informative account of advances in conflation, or automatic map compilation.

The use of map data involves other problems. Although interpolated boundaries on isopleth and proximal maps are objectively derived, they are often hypothetical (because the geographic phenomena may have a continuous rather than discrete distribution in space or because the discontinuity, such as a buried geological fault, may not be directly observable) and hence are arbitrary and/or intrinsically fuzzy ${ }^{65,124}$. Manual overlay analysis involves judgement and takes into account a number of factors, including the (spurious or lack of) accuracy and reliability of different data, a knowledge of the nature of underlying phenomena and the purpose and accuracy requirements of the analysis. Thus experts are able to extract appropriate and usable information from available, but often imperfect, data. Automatic overlay analysis does not, at present, provide scope for the inclusion of such conceptual and semantic knowledge and judgement.

Overlay analysis is also used for assumption-based disaggregation of spatial statistics for source BSUs and their reaggregation for target BSUs. The properties of spatial statistics are variable and considerable caution must be exercised in cross-coverage comparison of spatial statistics ${ }^{125}$. Thus some GIS applications of digital cartography are not just concerned with the attributes of places, but are also concerned with distributions in space for the manipulation of attribute data. In general overlay analysis of input or calculated polygons (for example, by defining buffer zones around point, line and area objects) requires positional data of high quality and cost.

A number of GIS applications, in government and in commerce, rely on the processing of proxy statistics. The emphasis here is on thematic mapping and on the accuracy of attribute data, rather than on the boundary data, for studying spatial patterns, relationships and anomalies. The data-collecting framework consists of basic population units (BPUs), rather than BSUs, and the boundaries representing the BPUs may be highly generalized and even undefined, as in the case of unit postcodes. Indeed, many such applications made little use of geographic maps in the past. This was mainly due to the financial costs and time delays involved in acquiring appropriate spatial descriptions. Area-based targetting of advertising mail and research on 
sociospatial structures have relied more on sophisticated, but blind, statistical analysis of population and other data for smaller and smaller areas. When spatial references were unavailable, data from different sources were related using non-spatial references, such as hierarchic codes for administrative areas and unit postcodes. Packages for statistical analysis such as SPSS (Statistical Package for the Social Sciences), SAS (Statistical Analysis System) and other ad-hoc software have formed the primary tools within this class of CIS, although cartographic diagrams have been used to study distributions in measurement space. Thus applications that are concerned primarily with the analysis of enumerated data, such as population, agricultural, retail and other censuses and surveys, focus on statistical populations rather than the containing spaces.

It is now widely recognized that a variety of factors at different stages in information collection, processing and analysis can introduce errors and unintended biases, leading to use of inappropriate information derived from these proxy statistics. Visualization is seen as a means of validation and as an instrument for generating insight. Owing to fashion, client pressure and the increasing availability of spatial descriptions, cartographic capabilities (for exmple, SPSS Craphics and SAS/Graph) are being appended to existing statistical packages; some mapping capabilities of SAS/Graph are illustrated in Carter?.

Smith et al. ${ }^{66}$ provided an indication of other types of CIS functions, which include network analysis. There is no doubt that many GIS include noncartographic components. Tomlinson Associates ${ }^{126}$ stressed this in their definition of CIS as a 'digital system for the analysis and manipulation of a full range of geographical data, with associated subsystems for digitizing and other forms of input and for cartography and other forms of display used in the context of decision making. The emphasis is clearly on the analysis and manipulation functions, and in the GIS field they provide the primary motivation for using digital methods; if the intention were not to analyze or manipulate, there would be no point in converting the geographical data to digital form in the first place'. Their review of the North American experience forms a valuable reference.

Unfortunately, this expert view alienates many map-based applications that derive significant benefits from the computerization of map-based storage, retrieval and display of information. It also takes a blinkered view of cartography as a form of display. Although manipulation and analysis functions tend to be central to some applications, these tend to be idiosyncratic; given the diversity of users and uses, they cannot form the core of general purpose CIS architectures. The definition of GIS, provided by Tomlinson Associates, is not fundamentally different from the modern definition of cartography provided by Cuptill and Starr ${ }^{34}$ but it places the emphasis on analytic functions rather than on the spatial database.

There is still a tendency towards promotion of general purpose state-of-the-art GIS. In the author's opinion, all-singing, all-dancing universal CIS do not provide the most effective environment for all users. CIS systems could be made more accessible and effective by architectures that facilitate product factoring and the development of configurations that meet the requirements of specific sets of users. From a systems developer's perspective, GIS 'add application specific modelling and manipulation capabilities to application oriented configurations of components in digital cartography' ${ }^{\prime 3}$. Loudon $^{65}$ provided a flavour of the specific requirements of geologists.

Coppock and Anderson ${ }^{112}$ (p 4) stated that 'Digital cartography interacts with CIS in three ways: by providing a framework, through national map coverages, for relating other categories of data; as a source of spatially referenced data in its own right; and as one of the methods of presenting the results of analyses of such data'. This paper has emphasized that maps are not just sources of data and forms of display: they are also devices for exploring and understanding data and for generating insight. Figure 1 accommodates not only the established applications of digital cartography but also the emerging interests in interactive cartography and in visual computing. GIS regard visual maps as useful but dispensable in many cases; they focus on the digital map. Although the spatial database is attracting a great deal of research effort at the present stage of evolution, in the long-term and from a user-centred perspective, visual and digital maps will be seen as complementary and equally important representations of spatial reality. CAD systems facilitate 'shallow' interaction with data models. Graphical information systems require 'deep' interaction with spatial databases through an interface, which could conceivably include multiple views controlled by a set of concurrent or parallel communicating processes.

\section{CONCLUSIONS}

Coppock and Anderson ${ }^{112}$ also stated that 'The collection of spatially-referenced data is, of course, as old as cartography, and every atlas is a form of GIS in that it brings together a wide variety of such data from different sources'. Both digital cartography and GIS are rapidly developing fields with outwardly expanding, fuzzy and overlapping concerns. Despite the wide and disparate concerns of the discipline, cartography has a well-defined and unique focus, namely the exploration, interpretation and communication of spatial forms, distributions and their relationships through maps. Digital cartography is the technology concerned with the construction and use of computer-based systems for the practice of cartography and its applications.

CIS is an application of cartography. The confusion surrounding CIS is mainly due to its lack of unique subject matter. It is insufficient to define CIS in terms of the functionality provided by state-of-the-art systems or as lying at the intersection of several disciplines. No doubt there are precedents for establishing a new science by carving out and combining components of existing disciplines - biochemistry provides an example. But such a regrouping of concerns is usually in response to the emergence of a unique substantive focus.

The promotion of the science of GIS does not appear to be based on such substantive criteria or academic 
tradition; instead, the rhetoric relies on shifting attention away from such issues onto the capabilities introduced by the new, now increasingly accessible, information technology. The Chorley Committee ${ }^{9}$ described GIS as 'the biggest step forward in the handling of geographic information since the invention of the map' and that 'such a system is as significant to spatial analysis as the inventions of the microscope and telescope were to science'. If GIS correspond to the telescope, then digital cartography and maps provide the lens in the scopes of all (geo)graphical information systems.

The invention of the telescope did not, however, spawn a new science - it launched a worthy technology. (Telescopy has been defined as the art or practice of constructing or of using the telescope.) In philosophical terms, the elevation of GIS to a science without first identifying its unique and central concerns will merely promote scientism. Let us not forget the debates over the word 'science' that preceded the renaming of the Social Science Research Council to the Economic and Social Research Council.

Some leading researchers and experts on CIS have proposed at least four candidate concerns as central: namely the interactive map interface, digital mapping, spatial analysis and applications. If we play down the impact of the changing tools of trade and rely on more substantive criteria, then interactive maps (both visual and digital) fall within the remit of cartography and computer science and the bulk of the analytical methods are essentially mathematical. Applications in turn belong to their respective disciplines - geography, geology, surveying and so on. This does not negate the immense value and commercial importance of GIS. It is a unique technology, drawing on several disciplines for systems development. Cartography, for its part, not only provides a unifying framework and data, it also provides objectives, knowledge, principles and techniques.

Smith et al. ${ }^{66}$ emphasized the need for systematic application of theories and techniques from several subfields of computer science and the integration of techniques developed in computer vision and image processing in the design and implementation of CIS. This paper has attempted to indicate to readers of Computer-Aided Design that the extraction of useful information from available spatial data is an art as much as it is a science. If the data and methods of cartography are divorced from, and manipulated without regard to, underlying meanings, principles, constraints and patterns of usage, then the resulting systems will be of limited value. Worse still, uncritical and deskilled use of such systems could result in disaster. The inflexible design of the emergency system for the fire brigade, in the case of the Hillsborough disaster ${ }^{127}$, provides a timely warning.

\section{ACKNOWLEDGEMENTS}

While accepting full responsibility for the views expressed in this paper, I would like to thank the following for their helpful comments: Dr Graham Kirby and Dr Mike Turner of the Cartographic Information Systems Research Group, David Fairbairn (Editor of the
Cartographic Journal), Mike Brand of Ordnance Survey (Northern Ireland) and the referees of this paper.

\section{REFERENCES}

1 International Cartographic Association Multilingual Dictionary of Technical Terms in Cartography Steiner, Wiesbaded, FRG (1973)

2 Morrison, J L 'Cartography: A milestone and its future' in Blakemore, $\mathbf{M}$ (ed.) Proc. Auto Carto London (1986) pp 1-12

3 Visvalingam, $\mathbf{M}$ 'Cartography, GIS and maps in perspective' Cartographic J. Vol 26 No 1 (1989) pp 26-32

4 Collinson, A The British Cartographic Society Newsletter No 1 (1989) p 1

5 Robinson, A H, Sale, R D, Morrison, J L and Meuhrcke, P C Elements of Cartography Wiley, New York (1984) 5th edition

6 Monmonier, M S Computer-Assisted Cartography: principles and prospects Prentice-Hall (1982)

7 Carter, J R Computer Mapping: Progress in the ' 80 s Association of American Geographers, Washington (1984)

8 Burrough, P A Principles of Geographical Information Systems for Land Resources Assessment Oxford University Press (1986)

9 UK Department of Environment Handling Ceographic Information HMSO (1987)

10 Bickmore, D P 'An automatic system of cartography' Paper presented to the International Cartographic Association meetings (July 31, 1964)

11 Blakemore, M (ed.) Proc. Auto Carto London Auto Carto London Ltd (1986)

12 Keates, J S Understanding Maps Longman (1982)

13 Maling, D H Coordinate Systems and Map Projections George Philip, London (1973)

14 Bertin, J Semiology of Craphics - Diagrams Networks Maps University of Wisconsin Press (1983) (original in French published in 1967)

15 Mackinlay, J 'Automating the design of graphical presentations of relational information' $A C M$ Trans. Graph. Vol 5 No 2 (1986) pp 110-141

16 Visvalingam, $\mathbf{M}$ and Kirby, $\mathbf{G} \mathbf{H}$ 'The impact of advances in IT on the cartographic interface in social planning' Department of Ceography Miscellaneous Series No 27 University of Hull (1984)

17 Cuff, D J and Mattson, M T Thematic Maps: their design and production Methuen, New York (1982)

18 Dickinson, G C Statistical Mapping and the Presentation of Statistics Edward Arnold (1973) 2nd edition 
19 Howe, M G National Atlas of Disease and Mortality in the United Kingdom Nelson, London, UK (1970)

20 Masters, U S 'The shepherds warning' Computer Images (June 1989) pp 17-21

21 Taylor, D R F 'The Canadian cartographer and the computer - present trends and future challenges' Canadian Cart. Vol 11 No 1 (1974) pp $35-44$

22 Rhind, D W 'Computer-aided cartography' Trans. IBC NS Vol 2 No 1 (1977) pp 71-97

23 Waugh, T C and McCalden, J GIMMS Reference Manual GIMMS Ltd, Edinburgh, UK (1983) Edn. 4.5 Edn. 4.5

24 Baecker, R M and Buxton, W A S (eds) Readings in Human-Computer Interaction - a multidisciplinary approach Morgan Kaufmann, California (1987) Chap. 7

25 Shneiderman, B Designing the User Interface Addison-Wesley (1987)

26 Lane, $M$ 'The rural areas database' Mapping Awareness Vol 2 No 2 (1988) pp 17-18

27 Walford, N, Lane, $\mathbf{M}$ and Shearman, J 'The rural areas database: a geographical information and mapping system on rural Britain' Trans. IBC NS Vol 14 No 2 (1989) pp 221-230

28 'Trade directory - data capture and conversion services' Mapping Awareness Vol 3 No 5 (1989) pp 19-25

29 Peuquet, D J 'A conceptual framework and comparison of spatial data models' Cartographica Vol 21 No 4 (1984) pp 66-113

30 Davis, J C and McCullagh, $\mathbf{M}$ J (eds) Display and Analysis of Spatial Data Wiley, New York (1975)

31 Harvard Laboratory for Computer Graphics and Spatial Analysis Harvard Library of Computer Graphics, Mapping Collection (19 Volumes) Harvard Graduate School of Design, Cambridge, MA, USA

32 Nagy, $\mathbf{G}$ and Wagle, $\mathbf{S}$ 'Geographic data processing ACM Comput. Surv. Vol 11 No 2 (1979) pp $139-181$

33 Freeman, $\mathbf{H}$ and Pieroni, G G (eds) Map Data Processing Academic Press (1980)

34 Guptill, S C and Starr, LE'The future of cartography in the information age' in Morrison, J L (ed.) Computer-Assisted Cartography Research and Development Report (ICA Commission C) (1984) pp 1-15

35 Starr, L E 'Mark II: the next step in digital systems development in the U.S. Geological Survey' in Blakemore, $\mathbf{M}$ (ed.) Proc. Auto Carto London (1986) pp 200-205

36 Haywood, P 'The OS Topographic Database Study' in Haywood, P (ed.) SORSA' 87 Durham Ordnance Survey, Southampton, UK (1987)
37 Openshaw, S and Mounsey, H 'Ceographic information systems and the $\mathrm{BBC}^{\prime}$ 's Domesday interactive videodisk' in. Blakemore, $\mathbf{M}$ (ed.) Proc. Auto Carto London (1986) pp 539-546

38 Clubb, $\mathbf{N}$ and Hilder, $\mathbf{D}$ 'Digital mapping at English Heritage' Mapping Awareness Vol 3 No 2 (1989) pp 18-21

39 Monmonier, $\mathbf{M} \mathbf{S}$ 'Trends in atlas development' Cartographica Vol 18 No 2 (1981) pp 187-213

40 Maling, D H Measurements from Maps: principles and methods of cartometry Pergamon 23, Oxford (1989)

41 Smith, N and Groom, P 'Testing of relational databases in Ordnance Survey research and development' in Haywood, P (ed.) SORSA '87 Durham Ordnance Survey, Southampton, UK (1987)

42 Brand, M J D 'The geographical information system for Northern Ireland' Mapping Awareness Vol 2 No 5 (1988) pp 18-21

43 Mitchell, W B, Guptill, S C, Anderson, K E, Fegeas, R G and Hallam, C A 'GIRAS: A Geographic Information Retrieval and Analysis System for handling land use and land cover data' US Geological Survey Professional Paper 1059 (1977)

44 Wade, P, Visvalingam, $M$ and Kirby, G H 'From line geometry to area topology' CISRG Discussion Paper 1 University of Hull (1986)

45 Kirby, $\mathbf{G} \mathbf{H}$, Visvalingam, $\mathbf{M}$ and Wade, $\mathbf{P}$ 'The recognition and representation of polygons with holes' Comput. J. Vol 32 No 6 (1989) pp 554-562

46 Ericksen, R H 'A polygon chaining algorithm to simplify area encoding' Comput. Environ. Urban Systems Vol 9 No 4 (1984) pp 237-245

47 ESRI ARC/INFO Users Manual - Version 3 Environmental Systems Research Institute, Redlands, California (1985)

48 Visvalingam, $\mathbf{M}$ and Sekouris, N S The management of digital map data using a relational database model' CISRC Special Issue No 3, University of Hull, UK (1989) 50 pp

49 De Simone, $\mathbf{M} \mathbf{D}$ 'Data structures and feature recognition: from the graphic map to a digital data base' Unpublished PhD Thesis CNAA (1986)

50 Durham, $\mathbf{T}$ 'Design programs that draw their own conclusions' Computing (6 July, 1989) pp 26-27

51 Wade, $\mathbf{P}$ 'Derivation of hierarchic area objects from O.S. feature coded vectors' in Visvalingam, M (ed.) Research based on Ordnance Survey Small-Scales Digital Data Cartographic Information Systems Research Group, University of Hull (1986) pp 61-70

52 Peucker, T K and Douglas, D H 'Detection of surface-specific points by local parallel processing of discrete terrain elevation data' Comput. Graph. Image Process. Vol 4 (1975) pp 375-387 
53 Mark, D M 'Automated detection of drainage networks from digital elevation models' Cartographica Vol 21 (1984) pp 168-178

54 Marks, D, Dozier, J and Frew, J Automated basin delineation from digital elevation data' CeoProcessing Vol 2 (1984) pp 299-311

55 Mason, D C, Corr, D G, Cross, A, Hogg, D C, Lawrence, $D$ H, Petrou, $M$ and Tailor, A M The use of digital map data in the segmentation and classification of remotely-sensed images' Int. J. CIS Vol 2 No 3 (1988) pp 195-216

56 Allder, W R and Elassal, A A 'USCS digital cartographic data standards. Digital line graphs from 1: 24000 scale maps' US Ceological Survey Circular 895 - C USGS (1984)

57 Peucker, $\mathbf{T} \mathrm{K}$ and Chrisman, N 'Cartographic data structures' Am. Cartographer Vol 2 No 1 (1975) pp 55-69

58 Corbett, J P 'Topological Principles in Cartography' Technical Paper 48 US Bureau of the Census, Washington (1979)

59 Marx, $\mathbf{R} \mathbf{W}$ 'The TIGER System: automating the geographic structure of the United States census' Government Publications Review 13 (1986) pp $181-201$

60 Kirby, G H, Visvalingam, $M$ and Wade, $P$ 'Storage and retrieval of topographic data using a relational database management system' in Haywood, $\mathbf{P}$ (ed.) SORSA '87 Durham Ordnance Survey, Southampton, UK (1987)

61 van Roessel, J W'Design of a spatial data structure using the relational normal forms' Int. I. GIS Vol 1 No 1 (1987) pp 33-50

62 Frank, A 'MapQuery: database query language for retrieval of geometric data and their graphical representation' Comput. Graph. Vol 16 (1982) pp $199-207$

63 van Roessel, J W and Fosnight, E A A relational approach to vector data structure conversion' Auto Carto 7 (1985) pp 541-551

64 Guptill, S C 'A new design for the US Geological Survey's national digital cartographic database' in Blakemore, M (ed.) Proc. Auto Carto London (1986) pp 10-18

65 Loudon, $\mathbf{T} \mathbf{V}$ 'Digital spatial models and geological maps $^{\prime}$ in Blakemore, $\mathbf{M}$ (ed.) Proc. Auto Carto London (1986) pp 60-65

66 Smith, T R, Menon, S, Star, J L and Estes, J E 'Requirements and principles for the implementation and construction of large-scale geographic information systems' Int. J. GIS Vol 1 No 1 (1987) pp 13-31

67 Green, N P A, Finch, S and Wiggins, J 'The 'state-of-the-art' Geographic Information Systems' Area Vol 17 No 4 (1985) pp 295-301
68 Abel, D J and Smith, J L 'A data structure and algorithm based on a linear key for rectangle retrieval problems' Comput. Vision, Craph. Image Process. Vol 24 No 1 (1983) pp 1-13

69 Samet, $\mathbf{H}$ 'Hierarchical representations of collections of small rectangles' ACM Comput. Surv. Vol 20 No 4 (1988) pp 271-309

70 Ballard, D H 'Strip trees: a hierarchical representation for curves CACM Vol 24 No 5 (1981) pp $370-321$

71 Shneier, $\mathbf{M}$ 'Two hierarchical linear feature representations: edge pyramids and edge quadtrees' Comput. Graph. Image Process. Vol 17 (1981) pp $211-224$

72 Tomlin, C D, Berwick, S H and Tomlin, S M 'Cartographic analysis of deer habitat utilization' in Teicholz, E and Berry, B J L (eds.) Computer Graphics and Environmental Planning Prentice-Hall (1983) pp 141-150

73 Ibbs, T J and Stevens, A 'Quadtree storage of vector data' Int. J. GIS Vol 2 No 1 (1988) pp 43-56

74 Gargantini, I 'An effective way to represent quadtrees' CACM Vol 25 No 12 (1982) pp 905-910

75 Lauzon, J P, Mark, D M, Kikuchi, L and Guevara, J A 'Two-dimensional run-encoding for quadtree representation' Comput. Vision, Graph. Image Process. Vol 30 (1985) pp 56-69

76 Diaz, B $\mathbf{M}$ and Bell, S B $\mathbf{M}$ (eds) Spatial Data Processing using Tesseral Methods Natural Environment Research Council, Swindon (1986)

77 Kleiner, A and Brassel, K E 'Hierarchical grid structures for static geographic data bases' in Blakemore, $M$ (ed.) Proc. Auto Carto London (1986) pp 485-496

78 Abraham, I $\mathbf{M}$ 'Automated cartographic line generalisation and scale-independent databases' Unpublished PhD Thesis CNAA (1989)

79 Slater, $M$ 'Segments on bit-mapped graphics displays' Softw. Pract. Exper. Vol 16 No 11 (1986) pp 965-980

80 Slater, $\mathbf{M}$, Davidson, $\mathbf{A}$ and $\mathbf{S m i t h}, \mathbf{M}$ Liberation from rectangles: a tiling method for dynamic modification of objects on raster displays' Comput. Graph. Vol 13 No 1 (1989) pp 83-89

81 Ordnance Survey The National Transfer Format Release 1.1 (January 1989)

82 DCDSTF - The Digital Cartographic Data Standands Task Force 'The proposed standard for digital cartographic data' American Cartographer Vol 15 No 1 (1988) (special issue)

83 Weights, B 'Kingston's GIS pilot set for promotion' Mapping Awareness Vol 3 No 2 (1989) pp 8-11

84 Hadley, C 'The Ordnance Survey 1:625000 database map production system' in Robinson, 
G R (ed.) Going Digital: Pros and Cons British Cartographic Society Special Publication Number 4 (1987) pp 30-49

85 Cook, A C 'A method for automatically annotating maps' in Visvalingam, $\mathbf{M}$ (ed.) Research based on Ordnance Survey Small-Scales Digital Data Cartographic information Systems Research Group, University of Hull (1986) pp 51-60

86 Clayton, P 'Carto 1:Automated Map Production (AMP)' OS News Vol 96 (1989) pp 13-15

87 Smith, N and Turner, J 'The Ordnance Survey topographic database: implications for the input and output of map data' in Earnshaw, R A (ed.) State of the Art in Computer Cartography BCS Displays Group, London (1987)

88 Essinger, $\mathbf{R}$ 'The philosophy and requirements of computer-aided graphic design in cartography' in Blakemore, $\mathbf{M}$ (ed.) Proc. Auto Carto London (1986) pp 189-196

89 McMaster, R B 'Automated line generalization' Cartographica Vol 24 No 2 (1987) pp 74-111

90 Muller, J-C 'Fractal and automated line generalization' Cartographic J. Vol 24 No 1 (1987) pp 27-34

91 Peucker, T K 'A theory of the cartographic line' Proc. Auto Carto /I Reston, Virginia (1975) pp $508-518$

92 McMaster, R B 'The geometric properties of numerical generalization' Geographical Analysis Vol 19 No 4 (1987) pp 330-346

93 Visvalingam, $\mathbf{M}$ and Whyatt, J D 'The DouglasPeucker algorithm for line simplification: reevaluation through visualization' Cartographic Information Systems Research Group Discussion Paper 6 University of Hull (1989)

94 Serpell, D Report of the Ordnance Survey Review Committee HSMO (1979)

95 Drinkwater, C R and Fielding, A P'The Hydrographic Department and the requirement for digital hydrographic data' in Blakemore, $\mathbf{M}$ (ed.) Proc. Auto Carto London (1986) pp 361-368

96 Brassel, $K$ E and Weibel, $R$ 'A review and conceptual framework for automated map generalisation' Int. J. GIS Vol 2 No 3 (1988) pp 229-243

97 Maver, T W 'Modelling the cityscape with geometry engines' Comput.-Aided Des. Vol 19 No 4 (1987) pp 193-196

98 Petrie, $\mathbf{G}$ and Kennie, $\mathbf{T}$ J M 'Terrain modelling in surveying and civil engineering' Comput.-Aided Des. Vol 19 No 4 (1987) pp 171-187

99 McCormick, B H, DeFanti, T A and Brown, M D (eds) 'Visualization in scientific computing' Comput. Graph. Vol 21 No 6 (1987)

100 Herr, $\mathbf{L}$ and Zaritsky, R Visualization: State of the Art ACM/SIGGRAPH video review Vol 30 (1988)
101 Turnbull, W $\mathbf{M}$ and Courlay, I 'Visual impact analysis: a case study of a computer-based system' Comput.-Aided Des. Vol 19 No 4 (1987) pp 197-202

102 Kraak, M J Computer-assisted Cartographical Threedimensional Imaging Techniques Delft University Press (1988)

103 Sasada, T T 'Drawing natural scenery by computer graphics' Comput.-Aided Des. Vol 19 No 4 (1987) pp 212-218

104 Gugan, D J and Dowman, I J 'Design and implementation of a digital photogrammetric system' Int. Archives of Photogrammetry and Remote Sensing Vol 26 No 2 (1986) pp 100-109

105 Donoho, D, Huber, P J and Thoma, H M'The use of kinematic displays to represent high dimensional data' in Eddy, W F (ed.) Computer Science and Statistics, Proc. of the 13th Symposium on the Interface Springer (1981)

106 Chambers, J M, Cleveland, W S, Kleiner, B and Tukey, P A Craphical Methods for Data Analysis Duxbery Press, Boston (1983)

107 Visvalingam, $\mathbf{M}$ 'Concept refinement through the graphic representation of large data sets' in Shackel, B (ed.) Interact ' 84 - Proceedings of the First IFIP Conference on Human-Computer Interaction North Holland (1985) pp 281-286

108 Visvalingam, $\mathbf{M}$ 'Problems in the design and implementation of a GKS-based user interface for a graphical information system' The GKS Review, Proc. Eurographics Workshop, ISO/TC97/SC24/N5 (September 1987)

109 Fotheringham, $S$ 'The US National Center for Geographic Information and Analysis' Mapping Awareness Vol 3 No 2 (1989) p 50

110 Shu, N C Visual Programming Van Nostrand Reinhold (1988)

111 Mark, D M'The use of quadtrees in Geographic Information Systems and spatial data handling' in Blakemore, M (ed.) Proc. Auto Carto London (1986) pp 517-526

112 Coppock, J T and Anderson, E K 'Editorial review' Int. J. GIS Vol 1 No 1 (1987) pp 3-11

113 Dale, P F 'Land information systems and the land parcel' Mapping Awareness Vol 2 No 2 (1988) pp $27-29$

114 Visvalingam, $M$ 'Issues relating to basic spatial units: Part 1' Mapping Awareness and Integrated Spatial Information Systems Vol 2 No 3 (1988) pp $40-42$

115 Visvalingam, $M$ 'Issues relating to basic spatial units: Part 2' Mapping Awareness and Integrated Spatial Information Systems Vol 2 No 4 (1988) pp 42-45

116 ICL 'ICL' Mapping Awareness Vol 3 No 2 (1989) pp 3-6 
117 Mahoney, R P 'An information centre' in Blakemore, M (ed.) Proc. Auto Carto London (1986) pp 190-199

118 Smith, $P$ 'Developments in the use of digital mapping in HM Land Registry' Mapping Awareness Vol 2 No 4 (1988) pp 37-41

119 Ives, $\mathbf{M}$ J and Lovett, $R$ 'Exchange of digital records between public utility digital mapping systems' in Blakemore, $\mathbf{M}$ (ed.) Proc. Auto Carto London (1986) pp 181-189

120 White, D 'A design for polygon overlay' in Dutton, G (ed.) First International Advanced Study Symposium on Topological Data Structures for Geographic Information Systems, Harvard Papers on CIS Vol 6 (Spatial Algorithms: Efficiency in Theory and Practice) Laboratory for Computer Graphics and Spatial Analysis, Graduate School of Design, Harvard University, Cambridge, MA, USA (1978)

121 Walker, P A and Moore, D M 'SIMPLE: an inductive modelling and mapping tool for spatially oriented data' Int. I. GIS Vol 2 No 4 (1988) pp 347-363
122 Sivertun, A, Reinelt, L E and Castensson, R 'A GIS method to aid in non-point source critical area analysis' Int. J. GIS Vol 2 No 4 (1988) pp 365-378

123 Saalfeld, A 'Conflation. Automated map compilation' Int. J. GIS Vol 2 No 3 (1988) pp 217-228

124 Burrough, P A 'Five reasons why Geographical Information Systems are not being used efficiently for land resources assessment' in Blakemore, $\mathbf{M}$ (ed.) Proc. Auto Carto London (1986) pp 139-147

125 Flowerdew, R 'Statistical methods for areal interpolation: predicting count data from a binary variable' Int. I. GIS (1990) (in press)

126 Tomlinson Associates 'Review of North American experience of current and potential uses of Geographical Information Systems' in Department of Environment (1987) pp 153-161

127 'The need for flexibility' Computer Weekly (22 June, 1989) p 17 